\title{
Fortnightly tidal asymmetry inversions and perspectives on sediment dynamics in a macrotidal estuary (Charente, France)
}

\author{
Toublanc Florence ${ }^{1,{ }^{*}}$, Brenon Isabelle ${ }^{1}$, Coulombier T. ${ }^{1}$, Le Moine Olivier ${ }^{2}$
}

\author{
${ }^{1}$ UMR 7266 LIENSs CNRS-University of La Rochelle, 2 rue Olympe de Gouges, 17000 La Rochelle, \\ France \\ 2 IFREMER-LERPC, Center of La Tremblade, Ronce-les-Bains, 17390 La Tremblade, France \\ * Corresponding author : Florence Toublanc, email address : florence.toublanc@univ-Ir.fr
}

\begin{abstract}
:
Tidal asymmetry is a phenomenon that characterises estuarine hydrodynamics and has a strong impact on sediment dynamics. Extensive research has been dedicated to studying tidal dynamics in semidiurnal macrotidal estuaries, highlighting several general principles. The ratio of flood to ebb peak velocities and differences in ebb and flood durations are often used to characterise the asymmetry encountered in estuaries.

In the Charente estuary (French Atlantic coast), water surface elevation data obtained using an ADCP (Acoustic Doppler Current Profiler) and a tide gauge show that the duration asymmetry undergoes inversions during the spring-neap tidal cycle. A two-dimensional hydrodynamics model is used to investigate the connection between spring-neap inversions of the tidal asymmetry and the harmonic composition of the tide. Different constituents (M2, S2, M4 and MS4) are considered at the open boundary. The results show that M4 and MS4 play a key role in the occurrence of these inversions. The influence of the morphology is also discussed and modifications of the bathymetry are performed to evaluate its impact. In the Charente estuary, the existence of both externally and internally generated overtides thus results in a spatially and fortnightly variable tidal asymmetry.
\end{abstract}

The modelled barotropic tidal currents are used to estimate the possible impact on sediment dynamics. The results suggest that asymmetry inversions tend to create sediment accumulation in an intermediate zone between the river mouth and Rochefort, located approximately $20 \mathrm{~km}$ upstream. 


\section{Highlights}

- We investigate tidal asymmetry inversions in the Charente estuary. Both M4 and MS4 overtides play a key role in duration and velocity asymmetries. Overtides are generated externally by interaction with the continental shelf. Interaction with the estuarine morphology also generates overtides internally.

Keywords: Estuary, Tidal asymmetry, Duration asymmetry, Ebb/flood dominance, Morphology, External/internal overtides, Sediment transport

\section{Introduction}

Investigating estuarine hydrodynamics is essential to understand these systems. Sanitary and/or economical issues are associated with these areas. At the interface between land and ocean, estuaries are indeed subject to important anthropic pressure. Many activities (such as fisheries, harbours and leisure) are strongly dependent on water quality and 
on sediment-related issues, such as siltation. Estuarine hydrodynamics and sediment dynamics are greatly determined by the interaction between the morphology of the area and the forcing variables, such as the river discharge and the tide. The resulting sediment transport and siltation can then provoke morphological changes that modify the estuarine dynamics. Understanding the constant interactions between the morphology and the hydro-sedimentary dynamics of estuaries is thus crucial to the management of these systems.

Although general principles can be deducted from the numerous studies conducted on estuarine hydrodynamics, each system has its peculiarities. This work focuses on the tidal asymmetry observed in the Charente estuary (Fig. 1). In this paper, we address tidal asymmetry in terms of duration (difference between ebb and flood durations) and peak velocity (ratio of flood to ebb peak velocities). Tidal distortion is commonly observed in estuaries, and it has been the object of many studies (Aubrey and Speer, 1985; Bolle et al., 2010; Dronkers, 1986; Fortunato and Oliveira, 2005; Friedrichs and Aubrey, 1988; Prandle, 2003). Depending on several characteristics (bathymetry, geometry and tidal regime), estuaries can be ebb-dominant if the ebb peak velocity is higher than the flood peak velocity, or flooddominant in the opposite case. Duration asymmetry can be associated with these dominances with shorter falling tides for ebb dominance (or rising tides for flood dominance), particularly if the mean water depth is greater than the tidal range.

This asymmetry not only characterises the hydrodynamics of the system, but also impacts the sediment dynamics. Current velocities have a direct impact on the bed shear stress, which is one of the control parameters for erosion processes, with the nature and state of the sedimentary bed (Mehta and Parchure, 2000; Tolhurst et al., 2000). Consequently, ebb or flood dominance is often completed by a dominance in terms of net sediment transport (Aubrey and Speer, 1985; Dronkers, 1986; Friedrichs and Aubrey, 1988; Fry and Aubrey, 1990). Ebb-dominated estuaries tend to export sediment, whereas flood-dominated estuaries generate upstream sediment transport (Allen et al., 1980; Dyer, 1997). On a long-term scale, sediment export or import could lead to morphological changes of sufficient importance to change the tidal asymmetry dominance (Dyer, 1997). Tidal asymmetry is also a driving mechanism controlling the formation and dynamics of the turbidity maximum in macrotidal estuaries (Allen et al., 1980). MacCready and Geyer (2010) investigated tidal asymmetry in vertical mixing, and the effect of the baroclinic pressure gradient. This phenomenon is not discussed in this paper, because a $2 \mathrm{D}$ vertically averaged model is used in the present work. Given the mixing conditions and the shallow depths in the Charente estuary, this approximation was considered to be adequate for the study proposed here.

Nonlinear interactions between the tide and the estuary provoke the growth of harmonics and compound tides of the main astronomical tidal constituents. Friedrichs and Aubrey (1988) studied the interaction between the M2 and M4 harmonic constituents of the tide to determine the direction of the asymmetry (flood- or ebb-dominated) and the degree of tidal distortion. Shorter rising tides correspond to a relative sea surface phase $\left(2 \varphi_{M 2}-\varphi_{M 4}\right)$ between $0^{\circ}$ and $180^{\circ}$. For shorter falling tides, the relative phase is between $180^{\circ}$ and $360^{\circ}$. The degree of tidal distortion caused by the estuary is indicated by the ratio of the two constituents' amplitudes $\left(a_{M 4} / a_{M 2}\right)$. The same parameters can be calculated for the velocity to provide an indication in terms of ebb/flood dominance. In a study by Friedrichs and Aubrey (1988), 
shorter falling tides correspond to ebb dominance, and shorter rising tides to flood dominance. The estuaries or inlets used in their study are mostly short (18 km maximum), and the geometry of the model inlet is rectangular. Thus, the parameters indicated above may not apply to all estuarine systems.

Non-linear tidal distortion is determined by two effects related to the estuary's morphological characteristics: (1) the frictional effects of the interaction between the tidal currents and the channel bottom, and (2) intertidal storage occurring in the presence of tidal flats or marshes (Boon and Byrne, 1981; Speer and Aubrey, 1985; Friedrichs and Aubrey, 1988; Speer et al., 1991). To evaluate the impact of the frictional effects, the ratio of the M2 offshore amplitude and the channel depth at mean sea level $(a / h)$ can be calculated (Speer and Aubrey, 1985; Friedrichs and Aubrey, 1988). This ratio gives an indication of the relative shalowness of the estuary (Speer et al., 1991). If $a / h$ is greater than 0.3, the frictional influence is greater at low water than at high water, causing flood dominance (Speer and Aubrey, 1985). The water level propagation is slowed at low water, leading to shorter rising tides and greater flood velocities. If $a / h$ is less than 0.2 , the channels are deep compared to the degree of asymmetry, the estuary is expected to be ebb-dominant (Friedrichs and Aubrey, 1988), ebb duration is shorter, and ebb velocities are usually stronger. For intermediate values of $a / h$, the system can be flood- or ebb- dominated, depending on the intertidal storage (Friedrichs and Aubrey, 1988). The intertidal storage effect is evaluated by calculating the ratio of the water volume stored between high and low water in intertidal areas, divided by the channel volume of water at mean sea level $\left(V_{s} / V_{c}\right)$ (Friedrichs and Aubrey, 1988). When $V_{s} / V_{c}$ is large in relation to $a / h$, the intertidal area is sufficiently large to slow the propagation of high water, causing longer flood durations and greater ebb velocities.

Many examples of flood-dominated systems can be found in the literature: Nauset Inlet, USA (Aubrey and Speer, 1985); Gironde estuary, France (Castaing and Allen, 1981); and Mandovi and Zuari estuaries, India (Manoj et al., 2009). Ebb-dominated systems are also represented throughout the world: Dyfi estuary, UK (Brown and Davies, 2010); Johor estuary, Malaysia (Hasan et al., 2013); and Okatee Creek, USA (Huang et al., 2008). Ebb-dominant and flood-dominant channels can also be observed in estuaries (Yangtze, China (Wang et al., 2008)). All these systems show no clear fortnightly dependent asymmetry inversions. Boon (1988) and Wang et al. (1999) have shown that spring-neap variability can modulate the amplitude ratio between M2 and M4 and the phase difference. Their results suggest that inversions following the spring-neap tidal cycle could occur, based on the evolution of the phase difference. They also showed that asymmetry is enhanced during spring tides. However, these studies do not show actual inversions in the sense of ebb and flood durations or peak velocities. It is therefore difficult to conclude whether systematic fortnightly asymmetry inversions occur in other coastal systems.

A large reduction of the cross-sectional area of the channel at the entrance of a bay can provoke a long-term asymmetry inversion from ebb to flood dominance (Boon and Byrne, 1981). In contrast, a weakly flood-dominant estuary could become ebb-dominant, due to the large import of sediment associated with strong flood currents, leading to an increase in the intertidal flats area (Boon and Byrne, 1981; Friedrichs and Aubrey, 1988; Speer and Aubrey, 1985). Along the border between Belgium and the Netherlands, deepening of the channels caused by dredging in the Scheldt estuary also caused a reduction in flood dominance, and an evolution towards ebb dominance (Bolle 


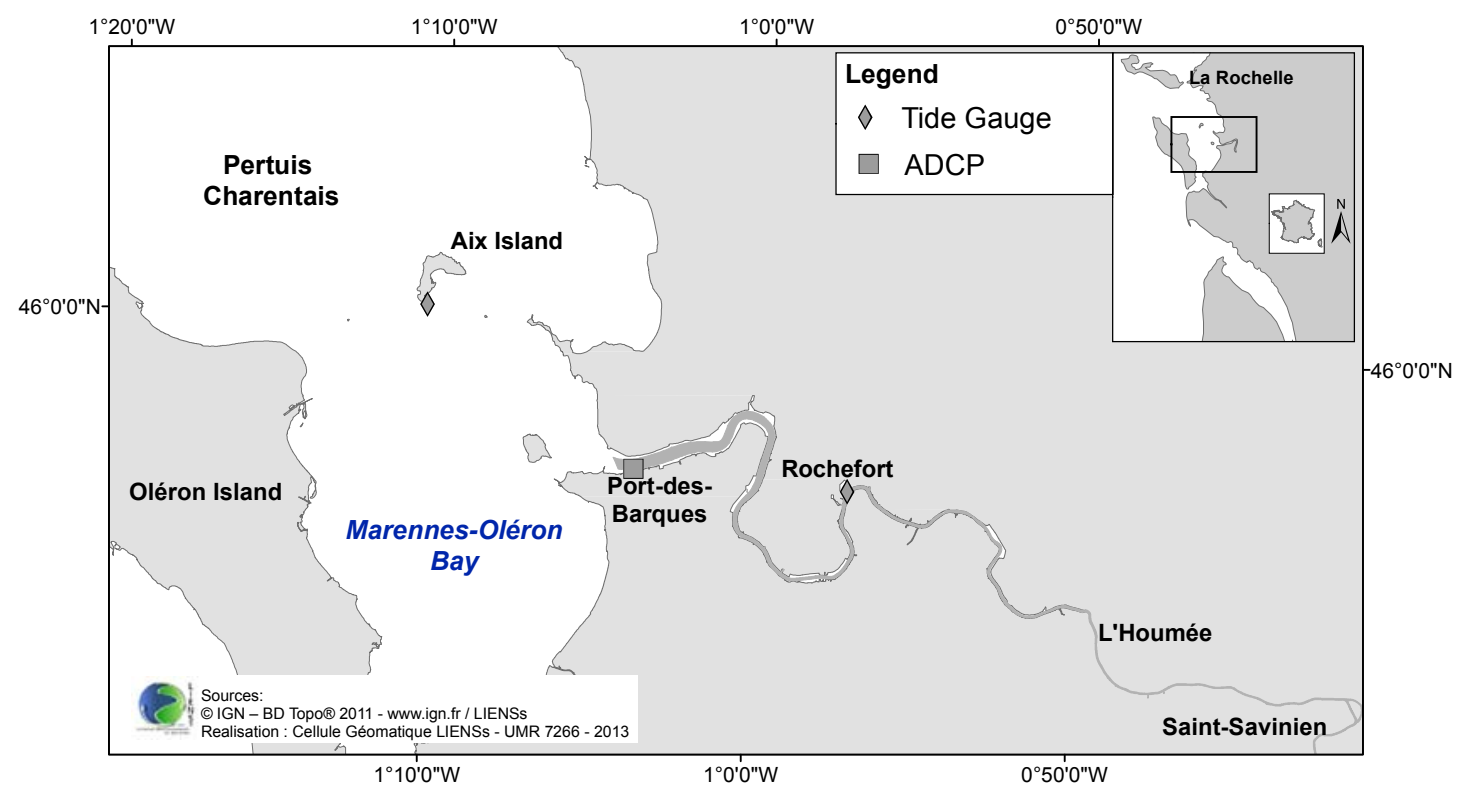

Figure 1: Charente River, from the Saint-Savinien dam to the mouth.

et al., 2010). Spring-neap asymmetry alternation has also been observed in the Skagit River (Nidzieko and Ralston, 2012) and the Murray Mouth coastal lagoon (Jewell et al., 2012), both of which are under the influence of mixed diurnal/semidiurnal tides.

These inversions are all consequences of significant long-term changes in estuarine characteristics or a mixed tidal regime, which is not the case in the Charente estuary. The objective of this study is to understand the tidal dynamics encountered in the area, that are leading to short-term inversions of the tidal asymmetry. The impact on barotropic tidal currents is investigated, and possible effects on sediment dynamics are discussed. In situ measurements and the MARS-3D hydrodynamic model (Lazure and Dumas, 2008) are used for this purpose.

\section{Study site}

The French Atlantic Coast is under the influence of a semidiurnal tide. The Charente estuary $\left(45^{\circ} 96^{\prime} \mathrm{N}, 1^{\circ} 00^{\prime} \mathrm{W}\right.$ ; Fig. 1), located to the south of La Rochelle (France) is small, shallow and characterised by the presence of large intertidal flats (Fig. 2b). The river flows into the Marennes-Oléron Bay, in the southern part of the Pertuis Charentais.

The bay's total surface is approximately $150 \mathrm{~km}^{2}$, with $60 \%$ composed of intertidal areas. The sediments in the estuary and in the eastern part of the Marennes-Oléron Bay are exclusively cohesive, with a very fine grain size (Strady et al., 2011). In the western part of the bay, the sediments are sandier (Tesson, 1973; Bertin et al., 2005).

The Charente tidal regime is macrotidal, with mean and maximum tidal ranges of 4.5 metres and 6.5 metres, 
respectively. The mean river discharge is $70 \mathrm{~m}^{3} / \mathrm{s}$. The lowest values are less than $10 \mathrm{~m}^{3} / \mathrm{s}$ and floods can reach 600 $700 \mathrm{~m}^{3} / \mathrm{s}$. The river catchment area is $10,000 \mathrm{~km}^{2}$ and the river length is $365 \mathrm{~km}$. A dam is located at Saint-Savinien, $50 \mathrm{~km}$ from the river mouth. This dam regulates the river discharge to avoid flooding and ensure the distribution of freshwater to the surrounding marshes and cultures.

The river is connected to the Marennes-Oléron Bay, in which the tide is already distorted. By applying a modified version of the Battisti and Clarke (1982) theory to the Bay of Biscay shelf, Le Cann (1990) showed that the quarterdiurnal tidal constituents (M4, MS4 and MN4) are strongly amplified shoreward, because of resonance occurring on the shelf. This behaviour was verified numerically by Bertin et al. (2012), who showed that the largest amplification by resonance occurred for MS4.

Water quality within the estuary represents a very important issue, because the Charente River is a source of fresh drinking water for the area. Extensive oyster farming in the Marennes-Oléron Bay and leisure activities are also strongly dependent on the Charente water quality and water level. According to Ravail et al. (1988), in summer, 90\% of the freshwater input in the bay comes from the Charente river.

\section{Materials and methods}

\subsection{Numerical modelling}

The MARS-3D (Model for Applications at Regional Scale) numerical model used in this study was fully described by Lazure and Dumas (2008). MARS-3D is a finite differences model that, when run in 2D, resolves the shallow water (or Saint-Venant) equations.

MARS-3D was used to determine the behaviour of the estuary in response to different hydrodynamic conditions. In particular, the effect of the harmonic composition of the tide at the boundaries was investigated.

A 2D configuration was developed to determine the impact of the tidal harmonic composition. Only the tide, computed from the SHOM CST-France model (Le Roy and Simon, 2003), and the actual daily river discharge were considered for the open boundary conditions. To specifically determine the impact of the harmonic composition of the tide, no atmospheric forcing was considered for this configuration. The roughness length was set at a relatively low value $(0.1 \mathrm{~mm})$, to represent accurately the variations of current velocities and water level. Indeed, the presence of fluid mud in the estuary tends to reduce friction and favour tidal propagation. The horizontal grid resolution is 30m (1405 x 766 grid points). Bathymetric datasets from 2003, 2007 and 2010 (Fig. 2a) were provided by several organizations (SHOM, Ifremer and EPTB Charente). Fig 2b shows only the bathymetry in the downstream part of the estuary, with the 2 metres below the mean sea level isobath displayed in black. With a mean tidal range of 4.5 meters, this figure shows the intertidal areas that are alternatively exposed and submerged most of the time.

Four configurations are used for this study, corresponding to four different harmonic compositions of the tide at the system's open boundaries (Table 1). For each case, elevations are determined from the SHOM CST-France model with the harmonic composition considered. Nesting is not used here. 




(a) Bathymetric data used for numerical modelling.

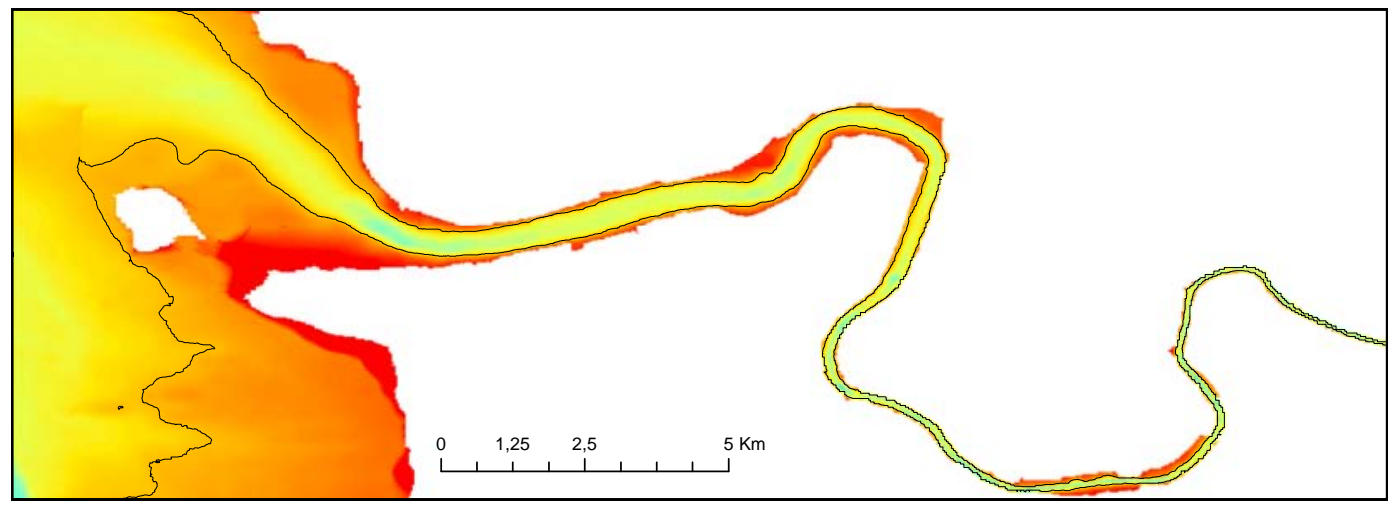

(b) Bathymetry in the downstream part of the Charente River. Dark line: isobath at 2 metres below the mean sea level.

Figure 2: Bathymetry of the Charente estuary.

$\mathrm{N} 2$ is not prescribed at the offshore boundary. This choice was justified by a test in which N2 was added (data not shown); the results showed no significant differences from the tidal asymmetry behaviour obtained in configuration D of this study.

\subsection{In situ measurements}

Fixed ADCP measurements (Sentinel-RDI, $1200 \mathrm{kHz}, 5$-minute sampling frequency) were performed in 2011 (from February 11 to April 8) at the mouth of the estuary, close to Port-des-Barques (Fig. 1). Tide gauge recordings are available at Rochefort and at Aix Island. For this period, the river discharge corresponds to average conditions and does not vary significantly (50 to $65 \mathrm{~m}^{3} / \mathrm{s}$ ). With these discharges, the estuarine Richardson number (Fischer, 1972) ranges from 0.02 to 0.64 , corresponding to well-mixed to partially mixed conditions. Highly stratified conditions occur for a very high river discharge and during neap tides. Depth was corrected using a Demerliac filter, to compare the data to the water levels obtained from the model without atmospheric forcing. Due to the ADCP emersion during low waters of spring tides, comparisons with velocities are not available. 
Table 1: Model configurations

\begin{tabular}{lcccc}
\hline Configuration & A & B & C & D \\
\hline Semi-diurnal constituents & M2 & M2,S2 & M2,S2 & M2,S2 \\
Quarter-diurnal constituents & - & - & M4 & M4,MS4 \\
\hline
\end{tabular}

\section{Results: data and numerical analysis}

\subsection{Observations}

Water levels and durations of ebb and flood were obtained from ADCP measurements at the mouth, and from tide gauge recordings at Rochefort (Fig. 3). Ebb durations correspond to the time between a water level maximum and its following minimum. The time between a water level minimum and its following maximum gives the flood duration. The dots representing these durations are plotted above the corresponding water level variations at each location. Dashed lines indicate the duration asymmetry inversions.

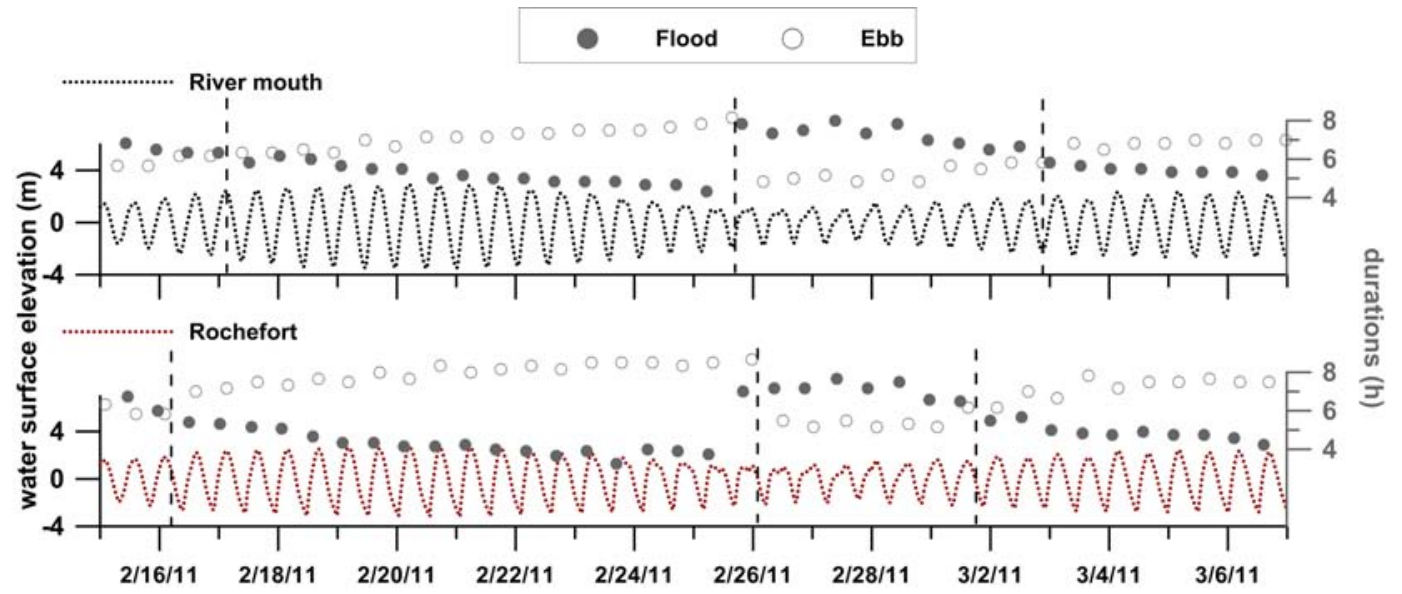

Figure 3: Surface elevation (left) and ebb and flood durations (right) at the river mouth (top) and Rochefort (bottom).

Inversion from a shorter flood to a shorter ebb occurs almost simultaneously at both locations: approximately at the beginning of neap tides (February, 25 to 26). Inversion from a shorter ebb to a shorter flood occurs earlier during neap tides at Rochefort. The level of distortion also differs between the two areas. When the flood is the shortest (between February 16 and February 26), the difference in durations is much greater at Rochefort (up to 4.8 hours) than at the river mouth (3.8 hours). In contrast, when the ebb is the shortest (between February 26 and March 2), the maximum difference in durations occurs at the river mouth (up to 3.2 hours), compared to 2.5 hours at Rochefort. Based on the tide gauge measurements at Rochefort, these inversions, in terms of durations, occur for a large set of river discharges, suggesting that baroclinic effects are not preponderant in this case. 


\subsection{Analytical analysis}

The amplitudes and phases of the principal tidal constituents at Aix Island are summarised in Table 2. These results were obtained from a 419-day harmonic analysis performed using T_Tide (Pawlowicz et al., 2002). Given the proximity of Aix Island to the estuary (approximately $5 \mathrm{~km}$ ), the results are considered representative of the tidal dynamics at the mouth. According to Friedrichs and Aubrey (1988), the relative sea surface phase $2 \varphi_{M 2}-$ $\varphi_{M 4}$ is $188.36^{\circ}$ and the amplitude ratio $a_{M 4} / a_{M 2}$ is 0.14 , suggesting that the ebb should be shorter in this area (Table 2). However, these calculations should be treated with caution as the geometry (funnel-shaped) and length (50 km between the mouth and the Saint-Savinien dam) of the Charente estuary differ from the setting used by Friedrichs and Aubrey (1988) (rectangular and short).

Table 2: Amplitudes and phases of the main tidal harmonic constituents (Aix Island)

\begin{tabular}{lcc}
\hline Harmonic constituents & Amplitude (cm) & Phase (deg) \\
\hline M2 & 179.80 & 97.41 \\
S2 & 64.32 & 130.78 \\
N2 & 37.62 & 77.99 \\
M4 & 25.44 & 6.46 \\
MS4 & 9.27 & 98.41 \\
\hline
\end{tabular}

Considering the geometric and tidal characteristics of the area, the two dimensionless parameters $a / h$ and $V_{s} / V_{c}$ were also calculated. At the Charente River mouth, $a / h$ is evaluated at 0.23 , with an M2 offshore amplitude of 1.75 metres and an average channel depth of 7.6 metres. This $a / h$ value is insufficient to form conclusions about the asymmetry dominance encountered. The intertidal storage ratio $\left(V_{s} / V_{c}\right)$ is estimated at 1 , which is large in comparison to a/h. These results suggest again that the tidal response of the estuary should be ebb-dominant. However, based on the in situ measurements at the river mouth presented in the previous paragraph, it appears that in the Charente estuary, the tidal asymmetry follows the spring-neap tidal cycle. The flood is shorter than the ebb during spring tides, and the opposite occurs during neap tides. These short-term inversions are observed systematically, and the level of distortion is modulated by the river flow and the tidal range.

\subsection{Numerical analysis}

To evaluate the impact of each component on the tidal asymmetry observed in the estuary, the results obtained from numerical modelling are compared using two criteria: ebb/flood durations and maximum ebb/flood velocities. No comparison of the absolute water surface level is performed because the objective is to study the distortion of the wave, and critical constituents needed to more precisely reproduce its variations are missing. However, comparisons of the modelled (configuration D) and observed amplitudes and phases of the main constituents considered are presented in Table 3. 
Table 3: Observed and modelled tidal amplitudes and phases of the main constituents at Aix Island

\begin{tabular}{lccccc}
\hline Constituent & & M2 & S2 & M4 & MS4 \\
\hline \multirow{4}{*}{ Amplitude (cm) } & Model & 177.5 & 62.50 & 25.60 & 10.23 \\
& Data & 179.8 & 64.32 & 25.44 & 9.27 \\
& Difference & 2.3 & 1.82 & 0.16 & 0.96 \\
\hline \multirow{3}{*}{ Phase (deg) } & Model & 96.95 & 129.95 & 10.38 & 103.82 \\
& Data & 97.41 & 130.78 & 6.46 & 98.41 \\
& Difference & 0.46 & 0.83 & 3.92 & 5.41 \\
\hline
\end{tabular}

These comparisons are not performed between the ADCP data and the modelled results at the mouth because the classical tools used for harmonic analysis appear to be unsuited for the Charente estuary. The results show that the amplitudes and phases of the quarter-diurnal constituents may change over time, which is likely due to the highly variable geometry of the flow section, with certain areas being inundated only during strong spring tides. In this context, wavelet analysis represents a possible solution to this issue (Flinchem and Jay, 2000; Grinsted et al., 2004). Such an analysis should be considered for further research but is beyond the scope of this study.

The numerical model can also be validated by comparing water surface elevations to the ADCP measurements (Port-des-Barques, Fig. 1) and tide gauge recordings (Rochefort). The current velocities obtained with the ADCP are averaged over the water column for comparison with the modelled barotropic velocities. For this validation, all 114 harmonic constituents available in CST-France are prescribed at the boundary. The mean absolute errors (MAE) and root mean square errors (RMSE) are calculated, in addition to a skill parameter (Equation 1), developed by Willmott (1981). This dimensionless parameter has been used in several estuarine studies (Li et al., 2005; Ma et al., 2011; Xing et al., 2012) to estimate their model's accuracy. A perfect agreement between model and observations corresponds to skill $=1$.

$$
\text { Skill }=1-\frac{\Sigma\left|X_{m o d}-X_{o b s}\right|^{2}}{\Sigma\left(\left|X_{\text {mod }}-X_{o b s}^{-}\right|+\left|X_{o b s}-X_{o b s}^{-}\right|\right)^{2}}
$$

The results show a good agreement between the modelled and observed water levels (Fig. 4). The skill parameter is 0.980 at Rochefort and 0.997 at the river mouth (Port-des-Barques). The RMSE and MAE values are 17.6 and 14.0 $\mathrm{cm}$ at the mouth and 38.7 and $33.2 \mathrm{~cm}$ at Rochefort, respectively. When compared to the mean tidal range, these errors are all less than $9 \%$. Errors on current velocities are calculated along the longitudinal (U) and meridional (V) directions. Skills are greater than 0.9 for both U and V, with RMSEs of 14.9 and $10.2 \mathrm{~cm} / \mathrm{s}$. 




Figure 4: Comparison between modelled and observed water levels at the river mouth (Port-des-Barques)

\subsubsection{Duration asymmetry}

Water surface elevations at the mouth over a full spring-neap tidal cycle are obtained for each configuration (Fig. 5) and the corresponding ebb and flood durations are presented. Asymmetry inversions are indicated by dashed vertical lines. Configurations A and B show almost no asymmetry inversion, with differences between ebb and flood durations below 0.5 and 0.78 hours, respectively. Adding M4 to the harmonic composition at the open boundary leads to an asymmetry inversion on February 27, the precise day of the lowest tidal range. The maximum difference between the ebb and flood durations is 2.5 hours for spring tides and -2.25 hours for neap tides. A second inversion from a shorter ebb to a shorter flood occurs on March 4, as the tidal range is increasing. If MS4 is considered (in configuration D), both inversions occur sooner and the maximum (ebb-flood) duration reaches 2.5 hours during spring tides, compared with 2 hours during neap tides.

At the upstream station, Rochefort (Fig. 1), the first difference is the response of the system to the basic configuration A (Fig. 6). When the tide is almost undistorted at the mouth, it is clear at Rochefort that an M2 incident tide induces a shorter flood (flood-ebb duration up to 2 hours). Configuration B produces the same type of results but with the modulation of the spring-neap tidal cycle, the level of distortion being stronger for high tidal ranges. Configurations $\mathrm{C}$ and D reproduce the asymmetry inversions observed at the mouth. However, ebbs are only shorter than floods by one hour maximum during neap tides, compared to a maximum duration difference of 4 hours during spring tides (when the flood is the shortest). When compared to the results at the mouth, the period during which ebbs are the shortest is also decreased by more than two days (Fig. 5).

Regarding the duration asymmetry, the mouth appears to be driven by an alternation between periods of shorter floods and shorter ebbs, with comparable levels of distortion. In contrast, the area of Rochefort is largely characterised by shorter floods. During neap tides, floods are only slightly longer than ebbs, and for a brief period of time. 


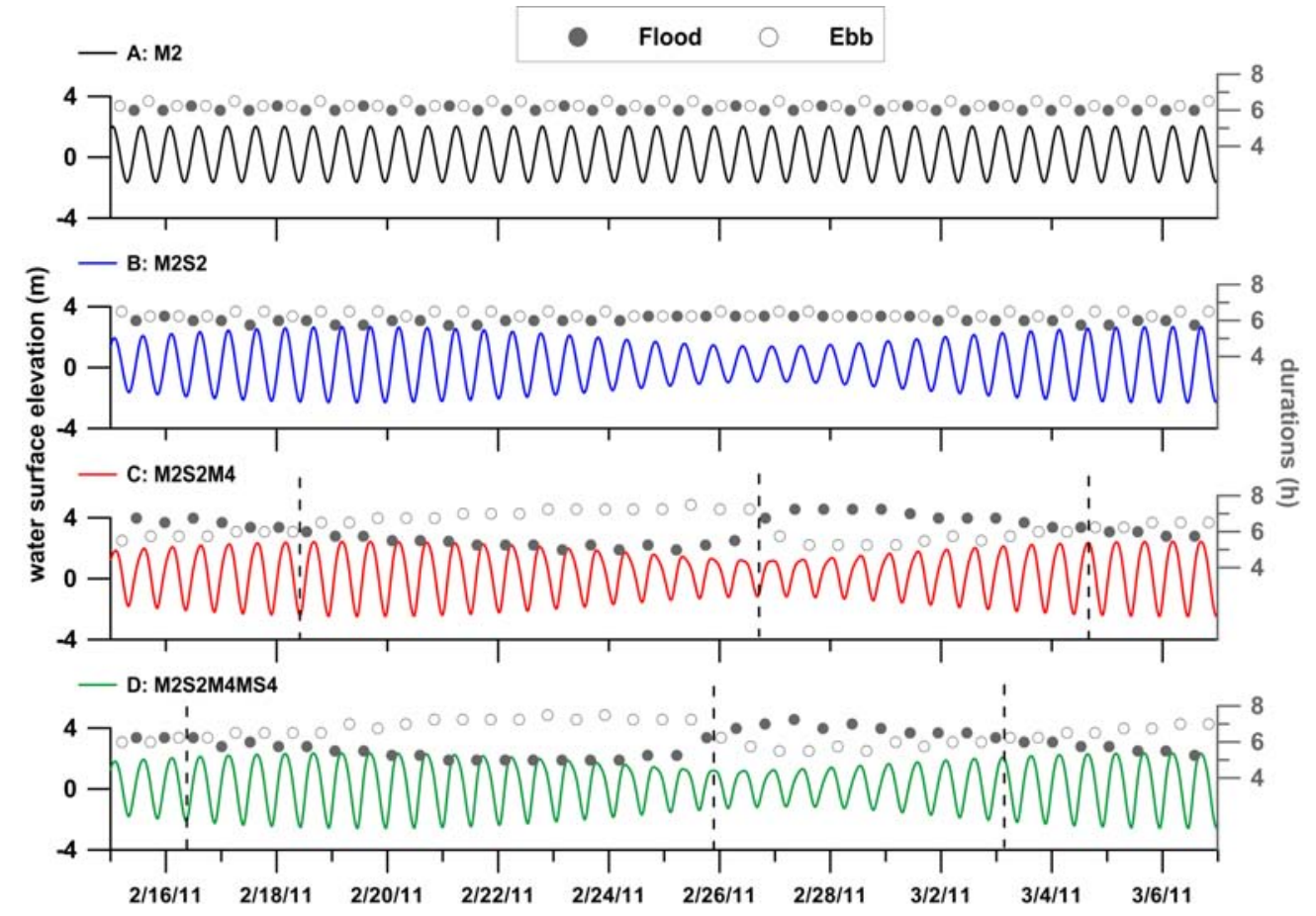

Figure 5: River mouth: water surface elevation (left) and ebb and flood durations (right) for each harmonic composition of the tide at the model boundary.

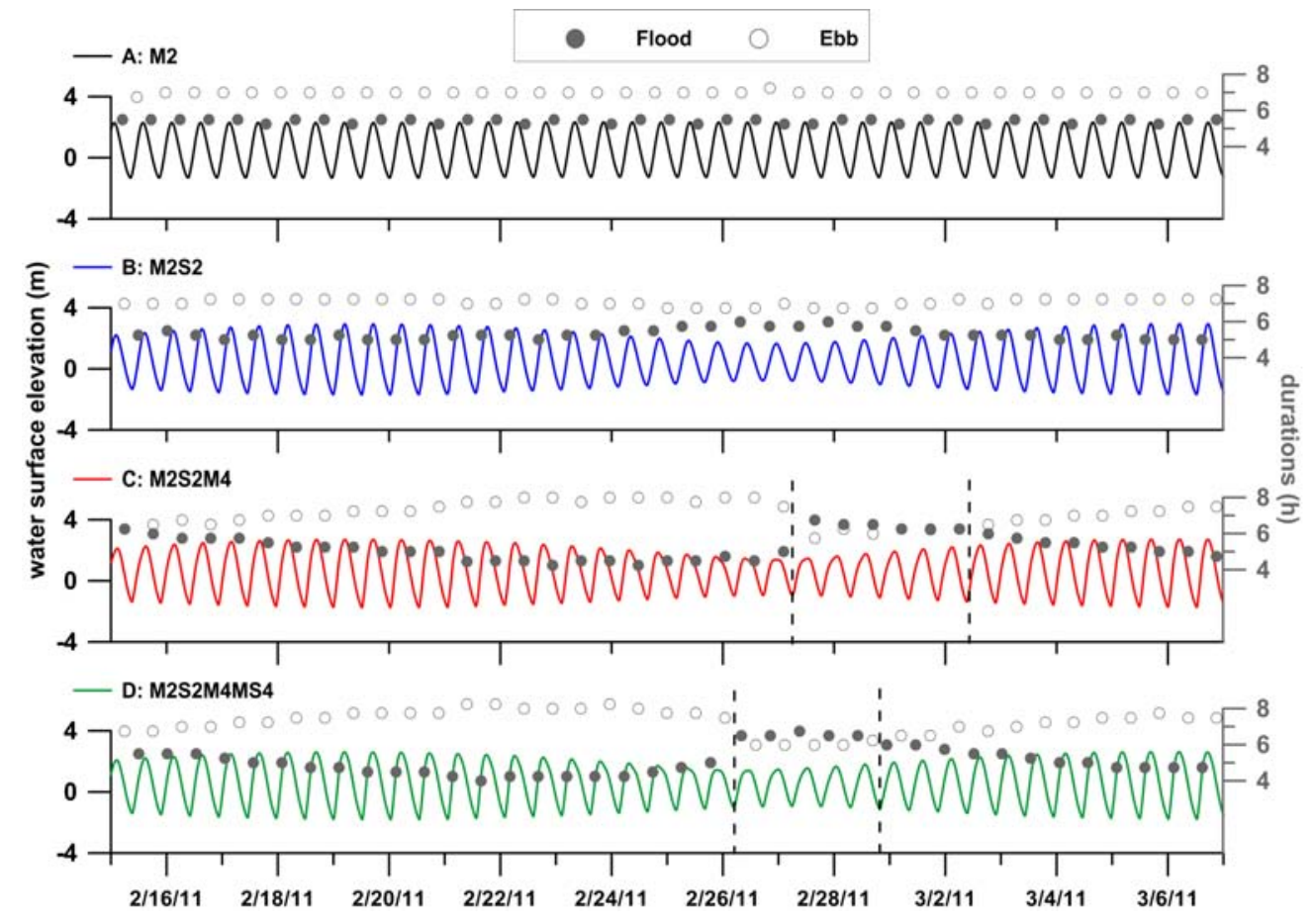

Figure 6: Rochefort: water surface elevation (left) and ebb and flood durations (right) for each harmonic composition of the tide at the model boundary. 


\subsubsection{Barotropic velocity asymmetry}

Tidal asymmetry in ebb and flood durations can be associated with an asymmetry in current velocities, causing shorter rising tides and longer falling tides to be combined with stronger flood currents and weaker ebb currents. In the opposite case (shorter falling tides), ebb currents are expected to be stronger. Figs. 7 and 8 present the same water level series as in Figs. 5 and 6, but with the addition of the ratio of the maximum flood velocity to the maximum ebb velocity.

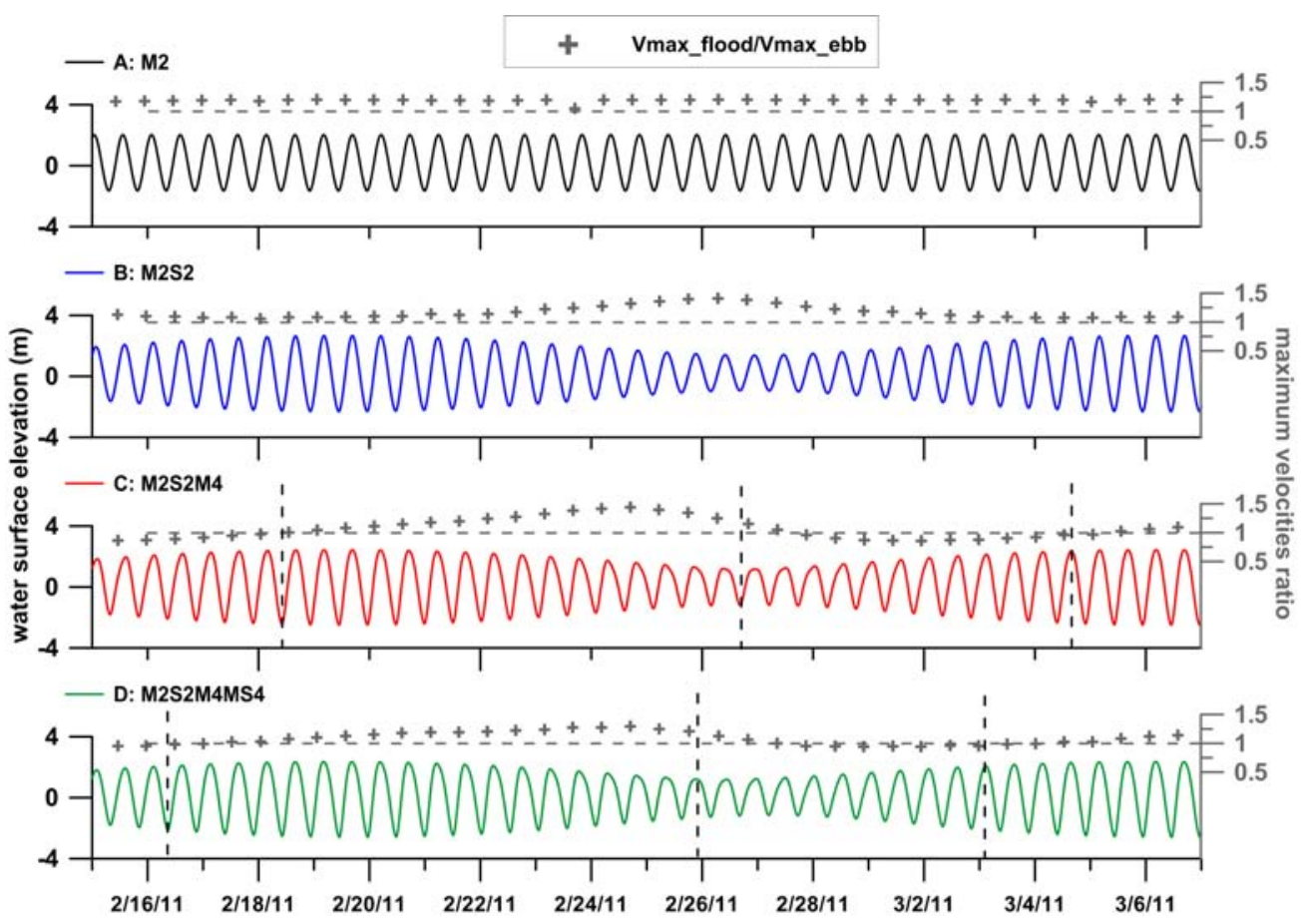

Figure 7: River mouth: water surface elevation (left) and velocity ratio $\operatorname{Vmax}_{f l o o d} / \operatorname{Vmax}_{e b b}$ (right).

A peak velocities ratio greater than 1 signifies that flood currents are stronger than ebb currents, indicating flood dominance. Ebb dominance occurs for a velocities ratio less than one. Dashed lines mark the asymmetry inversions observed with ebb and flood durations in the previous section. At the river mouth, the velocities ratio largely follows the same pattern as the duration asymmetry. Configuration A shows a constant slight flood dominance. Configuration B shows almost no asymmetry during spring tides, and flood dominance during neap tides. The quarter-diurnal constituents are considered in configurations $\mathrm{C}$ and D ; thus, asymmetry inversions that are almost in phase with duration asymmetry inversions are observed. However, when duration asymmetries are almost equivalent between ebb and flood dominance, velocity asymmetry is much stronger for flood dominance than it is for ebb dominance.

At Rochefort, the velocity asymmetry is ebb-dominated for the simplest M2 tidal forcing, whereas duration asymmetry is flood-dominated (Fig. 6). The same opposition is obtained for the M2,S2 tidal forcing, with a stronger ebb dominance during neap tides. As in the previous paragraph, configurations $\mathrm{C}$ and $\mathrm{D}$ show velocity asymmetry inversions but with higher phase differences compared with the duration asymmetries. Moreover, ebb dominance during 


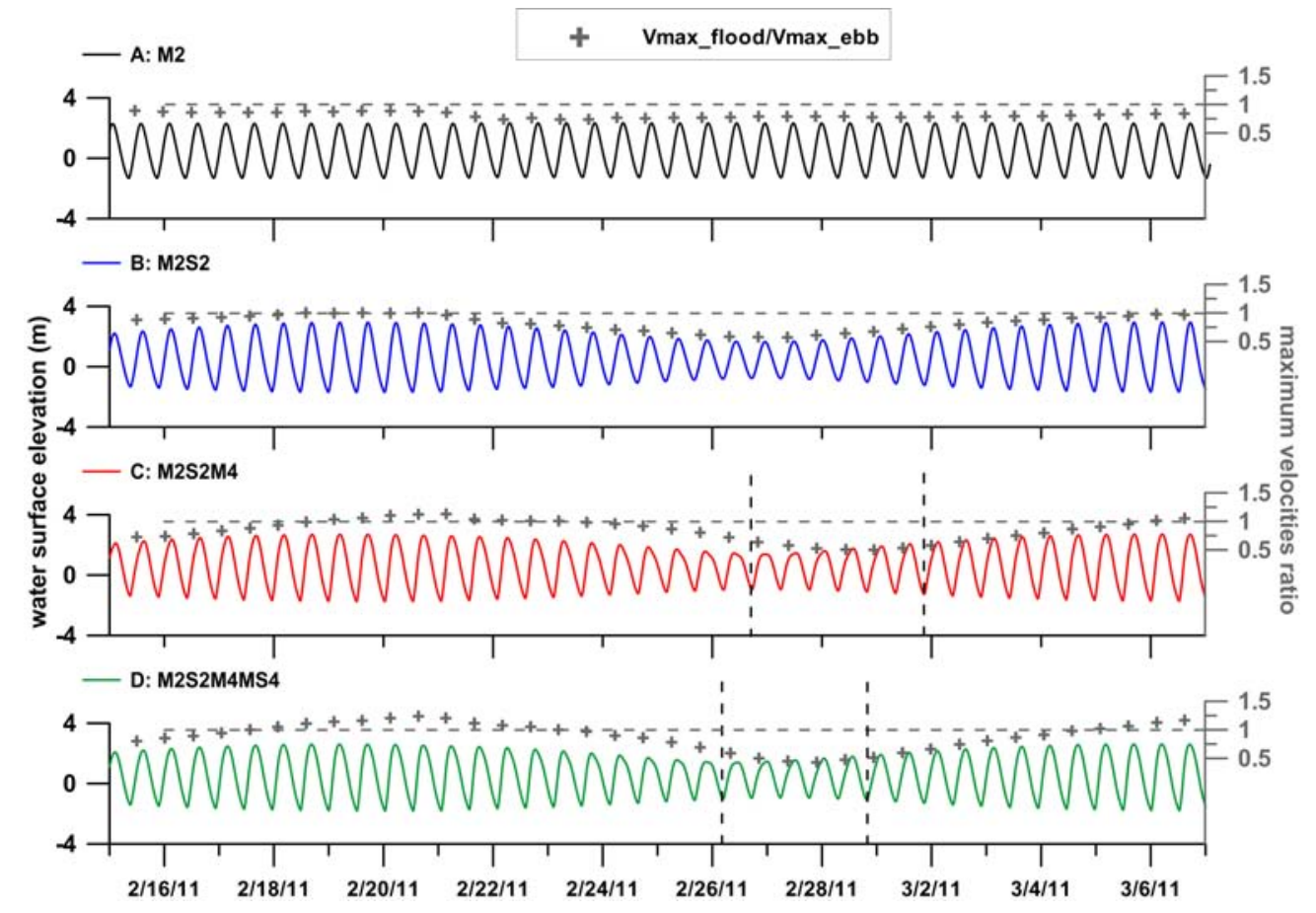

Figure 8: Rochefort: water surface elevation (left) and velocity ratio $\operatorname{Vmax}_{\text {flood }} / \operatorname{Vmax}_{e b b}$ (right).

\subsubsection{Summary and comparison with measurements}

The best agreement with the ADCP data is observed with the last configuration (M2, S2, M4 and MS4 tidal forcing), although differences remain for the exact moments of inversion.

The calculated ebb/flood durations and flood/ebb maximum velocities at the two locations are presented in Table 4. The difference between the values calculated and 1 (corresponding to a symmetric tide) gives an indication of the degree of tidal distortion. In the following paragraphs, the ebb/flood durations ratios and flood/ebb peak velocities ratios will be abbreviated DR and PVR, respectively.

At the mouth, the duration asymmetries are of the same order of magnitude, and display a good agreement with the ADCP data. Both the duration and velocity asymmetries are greater for shorter floods/flood dominance: the maximum DRs (1.5 for configuration D) and the maximum PVRs (1.3) are more distant from 1 than the minimum DRs (0.72) and the minimum PVRs (0.92).

The Rochefort area is characterised by a contrast between duration and velocity asymmetries. The duration asymmetries show a stronger duration difference when the flood is the shortest, which is confirmed by calculations performed with tide gauge data: the maximum DR is 2.32 , compared to a minimum of 0.67 . In contrast, the PVRs show a stronger ebb dominance: for configuration D, the minimum PVR is 0.43 , compared to a maximum PVR of 1.38 . This result is largely explained by the presence of intertidal flats in the area, which constrain the ebb flow for low water 
Table 4: Dimensionless parameters used to characterise the tidal asymmetry at the river mouth and at Rochefort, for all model configurations

\begin{tabular}{|c|c|c|c|c|c|}
\hline \multicolumn{6}{|c|}{ River mouth } \\
\hline Configuration & A & B & $\mathrm{C}$ & $\mathrm{D}$ & \multirow{2}{*}{ ADCP data } \\
\hline Harmonics & M2 & $\mathrm{M} 2, \mathrm{~S} 2$ & $\mathrm{M} 2, \mathrm{~S} 2, \mathrm{M} 4$ & $\mathrm{M} 2, \mathrm{~S} 2, \mathrm{M} 4, \mathrm{MS} 4$ & \\
\hline Minimum ebb/flood durations ratio & 1 & 0.89 & 0.7 & 0.72 & 0.6 \\
\hline Maximum ebb/flood durations ratio & 1.08 & 1.14 & 1.5 & 1.5 & 1.88 \\
\hline Minimum flood/ebb peak velocities ratio & 1.1 & 1.05 & 0.83 & 0.92 & - \\
\hline Maximum flood/ebb peak velocities ratio & 1.21 & 1.41 & 1.44 & 1.3 & - \\
\hline \multicolumn{6}{|c|}{ Rochefort } \\
\hline Configuration & A & B & $\mathrm{C}$ & $\mathrm{D}$ & \multirow{2}{*}{ Tide Gauge data } \\
\hline Harmonics & M2 & $\mathrm{M} 2, \mathrm{~S} 2$ & $\mathrm{M} 2, \mathrm{~S} 2, \mathrm{M} 4$ & $\mathrm{M} 2, \mathrm{~S} 2, \mathrm{M} 4, \mathrm{MS} 4$ & \\
\hline Minimum ebb/flood durations ratio & 1.23 & 1.04 & 0.85 & 0.85 & 0.67 \\
\hline Maximum ebb/flood durations ratio & 1.38 & 1.45 & 1.88 & 2.06 & 2.32 \\
\hline Minimum flood/ebb peak velocities ratio & 0.74 & 0.58 & 0.5 & 0.43 & - \\
\hline Maximum flood/ebb peak velocities ratio & 0.89 & 1 & 1.15 & 1.24 & - \\
\hline
\end{tabular}

levels. The maximum flood velocity is reached between 1.5 and 2 hours after the beginning the flood, compared to 3.5-5 hours for the maximum ebb velocity. During spring tides, even if the flood duration is shorter, the ebb currents are then equivalent or stronger than the flood currents (Fig. 9, left) because the flow is limited to the channel when the water level drops. During neap tides (Fig. 9, right), tidal flats slow the flood tide when the water level reaches their height: friction induces a decrease in flood velocities.
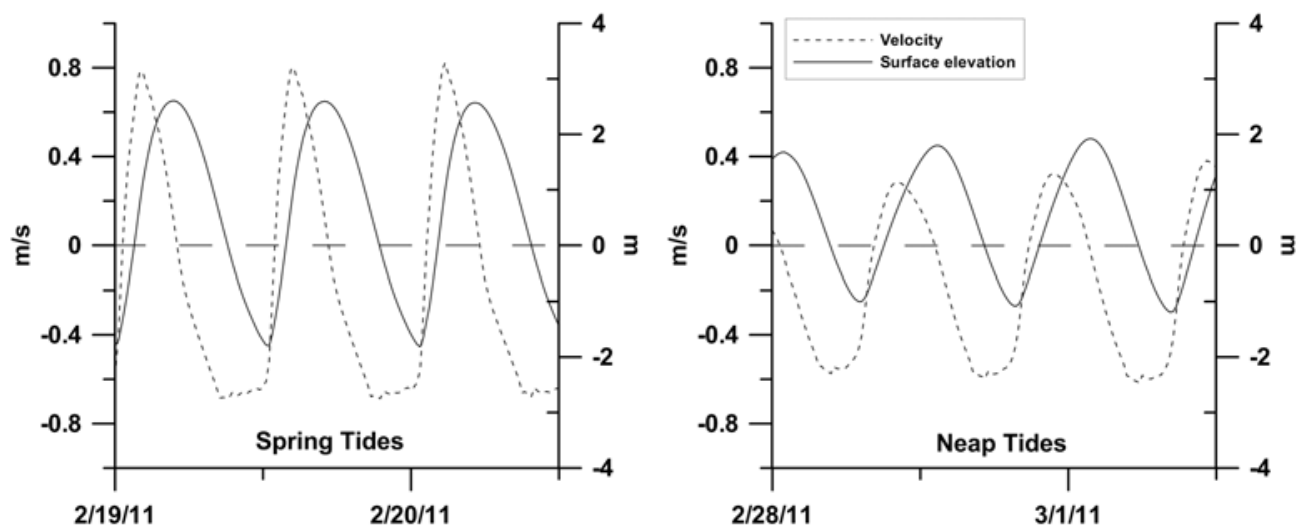

Figure 9: Current velocity (positive: flood, negative: ebb) and water surface elevation at Rochefort for spring (left) and neap tides (right). 


\section{Discussion}

The results obtained from both observations and numerical modelling show that the spring-neap tidal cycle and the localisation greatly impact the tidal asymmetry observed in the Charente estuary. The most striking feature of the observed processes resides in the high-amplitude asymmetry changes: from ebb to flood dominance, and vice versa. In the following sections, we explore the possible causes of this peculiar behaviour and discuss its possible impact on the estuarine sediment dynamics.

\subsection{Impacts of the incident tide and morphology on the Charente tidal asymmetry}

\subsubsection{The key role of quarter-diurnal constituents}

The first part of the study demonstrated the essential role played by quarter-diurnal constituents in the tidal asymmetry inversions observed in the Charente estuary. Interaction between the M4 harmonic and the principal M2 constituent had previously been demonstrated (Aubrey and Speer, 1985; Friedrichs and Aubrey, 1988). However, the introduction of the M4 harmonic into the model is necessary but not sufficient to reproduce the asymmetry observed in the estuary. When the MS4 harmonic is considered, asymmetry inversions are reproduced in phase with observations. In the Charente estuary, tidal asymmetry thus results from the combination of the well-known estuarine distortion of the semidiurnal tide and the incidence of a tidal wave already composed of high-amplitude harmonics, which develop from the interaction with the continental shelf (Le Cann, 1990; Bertin et al., 2012).

The influence of the low-frequency constituent MsF could also be considered as a possible explanation for these inversions. The interaction between M2 and S2 inside the estuary indeed generates this constituent, with an MsF amplitude close to $12 \mathrm{~cm}$. However, if the asymmetry inversions were related to MsF, they would occur in phase with the spring-neap tidal cycle. In the Charente case, they occur as the tidal range decreases and increases.

As shown in this paper, tidal asymmetry inversions are linked to the presence of significant quarter-diurnal consituents in the incident tide, with amplitudes exceeding $0.1 \mathrm{~m}$. This unusual development of quarter-diurnal constituents before the tidal wave reaches shallow waters and inner estuaries was shown to result from interactions with the continental shelf in the Bay of Biscay by Le Cann (1990). Only a few areas of the world ocean (Fig. 10) are characterised by distorted incident tides (e.g. Patagonian Shelf, North Sea, Yellow Sea), where small coastal systems such as the Charente estuary likely remain unstudied. Further research in these areas could augment the present study, by comparing morphological differences within the estuaries and/or bays, as well as the possible impacts on tidal propagation associated with these differences.

\subsubsection{Locally-vs remotely-generated overtides}

The idea of a combination of two "types" of overtides (externally and internally generated) is reinforced by harmonic analyses performed on the modelling results (Table 5) using T_Tide (Pawlowicz et al., 2002). As stated previously, it is difficult to use classical harmonic analysis approaches in the Charente estuary. The flow section is highly variable, which induces significant errors when harmonic analyses are performed on in situ data. However, the model 


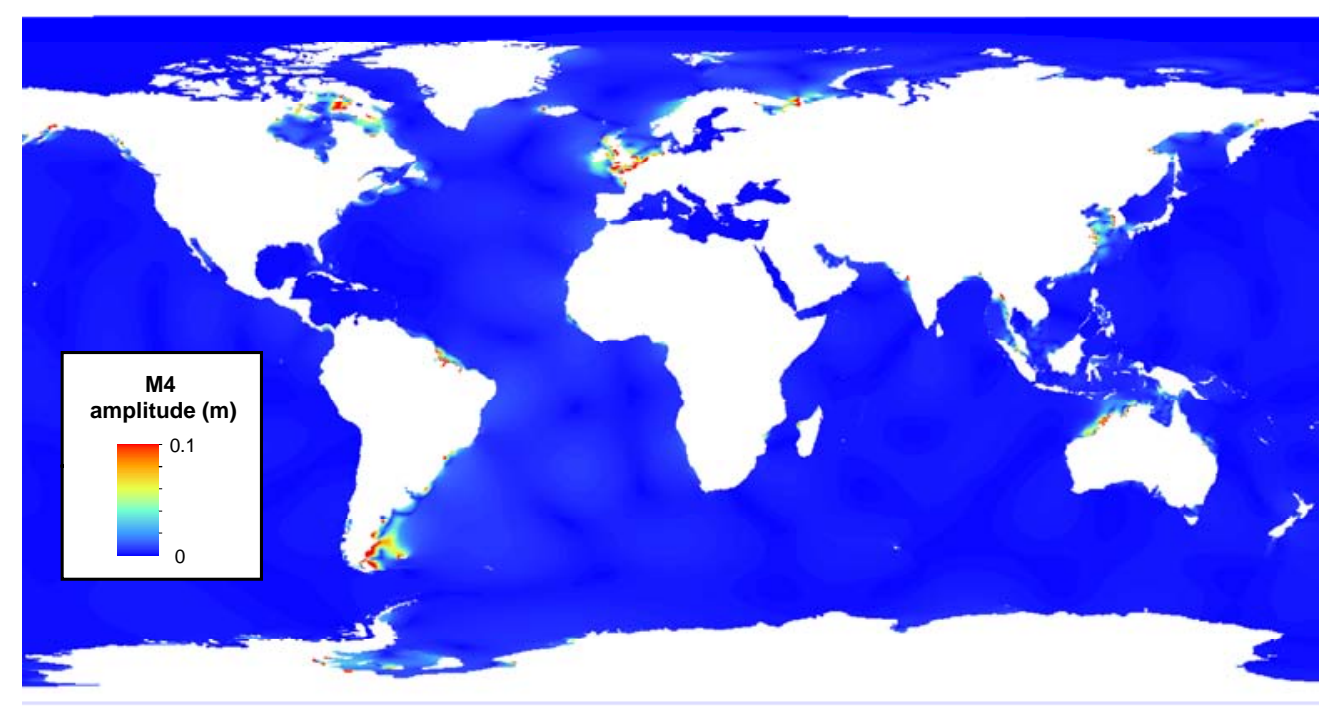

Figure 10: M4 amplitude (m) in the world ocean, extracted from FES 2004

configurations used here are idealised, in comparison to the complexity of in situ data, since the harmonic composition of the tide at the boundary is limited to 4 constituents. Thus, the utilisation of harmonic analyses is possible, as long as the results are compared the results between two model configurations that are close and simplified in terms of tidal composition at the open boundary.

The amplitudes and phases of M4 in cases A and C illustrate the existence of externally and internally generated overtides. At the river mouth, the differences in M4 amplitude are higher than at Rochefort (Table 5 (top)), due to a greater distortion of the tide by the interaction with the estuary when moving upstream. At Rochefort, $66 \%$ of the M4 amplitude is due to internal tide-estuary interactions, compared to $13 \%$ at the river mouth. The M4 phase differences between cases $\mathrm{A}$ and $\mathrm{C}$, both at Rochefort $\left(56.5^{\circ}\right)$ and at the river mouth $\left(45^{\circ}\right)$, also indicate that the overtides are generated both internally and externally. The same observations can be made on the MS4 coumpound harmonic, that results from the interactions between $\mathrm{M} 2$ and S2, by comparing the amplitudes and phases differences between cases B and D. (Table 5 (bottom)). A the river mouth, $23 \%$ of the MS4 amplitude is generated internally, compared to 63 $\%$ at Rochefort. The phase difference is smaller at the river mouth $\left(4.5^{\circ}\right)$ than at Rochefort $\left(13.5^{\circ}\right)$.

The Charente estuary exhibits the following temporally and spatially dependent tidal asymmetries. (1) At the mouth, asymmetry follows the spring-neap variations, with corresponding duration and velocity asymmetries (Fig. 5 and Fig. 7). (2) Upstream, asymmetry is still subject to spring-neap modulations ; however, velocity asymmetry is mostly ebb-dominated (Fig. 8), whereas the flood duration is shorter than ebb duration most of the time (Fig. 6). In the Rochefort area, tidal flats provoke strong variations in the flow section from high water to low water. The flow is strongly constrained at low water values and larger peak ebb velocities can thus be observed, even if the ebb is longer than the flood (Dronkers, 1986; Brown and Davies, 2010). Depth variations must also be considered. 
Table 5: Amplitudes and phases of M2, S2, M4 and MS4 at the river mouth and at Rochefort for different model configurations

\begin{tabular}{lccccc}
\hline & & \multicolumn{2}{c}{ Amp (cm) } & \multicolumn{2}{c}{ Phase (deg) } \\
\hline Model Configuration & & A & C & A & C \\
\hline \multirow{2}{*}{ River mouth } & M2 & 180.57 & 178.85 & 101.14 & 100.88 \\
& M4 & 3.69 & 28.18 & 73.73 & 28.80 \\
\hline \multirow{2}{*}{ Rochefort } & M2 & 172.69 & 163.42 & 122.38 & 122.65 \\
& M4 & 15.77 & 23.97 & 159.41 & 102.78 \\
\hline \hline \multirow{2}{*}{ Model configuration } & & Amp $(\mathrm{cm})$ & Phase & $(\mathrm{deg})$ \\
\hline \multirow{3}{*}{ River mouth } & & B & D & B & D \\
& M2 & 180.48 & 179.66 & 100.80 & 101.56 \\
& S2 & 64.98 & 63.28 & 134.64 & 134.47 \\
Rochefort & MS4 & 3.08 & 13.54 & 121.05 & 116.60 \\
\hline & M2 & 170.08 & 163.35 & 122.84 & 123.50 \\
& S2 & 56.30 & 53.08 & 159.92 & 157.53 \\
& MS4 & 11.80 & 18.73 & 204.99 & 191.27 \\
\hline
\end{tabular}

At the river mouth, the mean channel depth is approximately 7.5 metres. Deeper areas are found upstream, with depths varying between 7 and 11 metres. Around Rochefort, the mean channel depth is close to 9 metres. As shown by several studies (Brown and Davies, 2010; Friedrichs and Aubrey, 1988; Moore et al., 2009; Wang et al., 2002) deeper channels favour ebb dominance, whereas shallower waters often lead to flood dominance. The combination of average depths and intertidal flats at the mouth would thus favour asymmetry inversions following the tidal range. Deeper upstream areas, which are also associated with intertidal flats, would lead to ebb dominance most of the time, even if asymmetry inversions were observed.

To more precisely evaluate the impact of the estuary's morphology, two tests involving different bathymetry modifications are conducted. For the first test, the mean water level is increased by a metre. This modification provokes an increase in both the channel depth and the intertidal flats depth. For configuration D (M2, S2, M4 and MS4 at the open boundary), the results show that velocity asymmetry inversions no longer occur at the river mouth: the estuary is always flood-dominant at this location. The peak velocities ratio increases by $11 \%$. Ebb durations are also longer than for the original bathymetry. At Rochefort, the peak velocities ratio still increases during spring tides and reaches values larger than one (flood dominance). However, its maximum value is 1.05 compared to 1.24 (12.5\% drop on average), and the period of flood dominance is reduced (3 tidal cycles compared to 12). An increase in the mean water level (equivalent to a global deepening of the estuary) thus tends to eliminate velocity asymmetry inversions in the estuary. For configuration A (M2 at the open boundary), this modification enhances the dominances observed with 
the original bathymetry (flood dominance at the mouth, ebb dominance at Rochefort), which is consistent with the previous results.

For the second test, only the tidals flats are deepened: the intertidal areas above the mean sea level are now at mean sea level. Simulations are performed only with the M2 constituent at the open boundary, to observe the possible impact of this modification on the flood dominance at the river mouth and the ebb dominance at Rochefort. At the river mouth, both flood and ebb velocities are enhanced by this modification but the peak velocities ratio globally decreases (9.6\% drop). The calculated maximum and minimum peak velocities ratios over the simulated period are 1.11 and 1.04, respectively. With the original bathymetry (Table 4), these values were 1.21 and 1.10 . These results indicate that flood dominance is reduced at the river mouth, when the tidal flats are slightly deepened. At Rochefort, the difference is less obvious than at the river mouth: the calculated maximum and minimum ratios are 0.93 and 0.75 , compared to 0.89 and 0.74 for the original bathymetry (Table 4 ). On average, there is a $2.2 \%$ increase in the peak velocities ratio. Ebb dominance is thus slightly reduced by this modification of tidal flats depth.

Fortunato and Oliveira (2005) studied the influence of intertidal flats on tidal asymmetry. They showed that the depth of the tidal flats maximising ebb dominance is at mean water level or slightly above, and depends on the tidal amplitude and the extent of the tidal flats. At the mouth of the Charente estuary, intertidal areas are large (up to 75 $\%$ of the width), and mostly at depths below the mean water level. When the depths above the mean water level are reduced to this value, flood dominance remains, but decreases significantly. In contrast, when the tidal flats and the channel are deepened over the entire area, flood dominance is enhanced. Fortunato and Oliveira (2005) showed that when the tidal flats are below the mean water level, tidal amplitude strongly influences tidal asymmetry: if the flats are not exposed at low tide, the estuary tends to be flood-dominant. With the original bathymetry, intertidal flats at the river mouth are exposed for all tidal ranges, which is not the case after increasing the mean water level.

At Rochefort, tidal flats are mostly at depths above the mean water level, and they can represent up to $50 \%$ of the width. When they are deepened to be at the mean water level, ebb dominance is slighlty reduced but the modification is smaller than at the river mouth. This result is consistent with the study of Fortunato and Oliveira (2005). However, when all the bathymetry is deepened, ebb dominance is enhanced. In this case, the deepening of the channel, which tends to promote ebb dominance, appears to be playing a greater role than the modification of intertidal depths.

The modifications made on the Charente estuary morphology provoke significant changes to the tidal asymmetry. These results confirm that tidal asymmetry is the consequence of complex interactions between the incident tide, which is already distorted in this case, and the morphology of the estuary. Both the intertidal flats and the channel depth have an impact on tidal distortion.

\subsection{Perspectives on sediment dynamics}

\subsubsection{Net sediment transport}

Brown and Davies (2010) proposed two ratios to determine the ebb or flood dominance of sediment transport over a cross-section: (1) the ratio of the peak flood velocity to the peak ebb velocity $u_{p}$ and (2) the ratio of the flood and 




Figure 11: Peak flow velocities ratio against the duration ratio at the river mouth and Rochefort.

ebb durations during which the velocity is greater than a threshold for sediment movement $T_{d}$. Ebb dominance is obtained for values of $u_{p}$ less than 1 and values of $T_{d}$ greater than 1. However, Brown and Davies (2010) also show that ebb dominance can be obtained for $u_{p}<1.2$ and $T_{d}<1$. In this case, ebb current velocities are higher than $\left(u_{p}<\right.$ $1)$ or close to flood current velocities $\left(1<u_{p}<1.2\right)$. Combined with longer ebb duration $\left(T_{d}<1\right)$, this configuration results in ebb-dominant net transport. Charente sediments are a very fine, exclusively muddy sediment, with a mean median grain size of $9 \mu \mathrm{m}$ close to the mouth (Strady et al., 2011). Moreover, as shown in Fig. 9, periods of slack water with very low velocities are short. In this paper, the velocity threshold is therefore considered to be exceeded for all ebb and flood durations, because very fine sediments in fluid mud can be easily resuspended in the water column by entrainment (Mehta, 1991). Calculations are performed over a full spring-neap tidal cycle to equally represent all possibilities, and $u_{p}$ is plotted against $T_{d}$ (Fig. 11).

Zone 1 is representative of the typical flood asymmetry, with short and rapidly rising tides. Zone 2 is populated by points with longer rising tides but higher flood velocities. Typical ebb-dominant asymmetry corresponds to zone 3 , and zone 4 is characterised by longer falling tides but higher ebb velocities. Following the criteria of Brown and Davies (2010), points located in zone 1 below the solid line $\left(u_{p}<1.2\right.$ and $\left.T_{d}<1\right)$ and in zones 3 and $4\left(u_{p}<1\right.$ and $T_{d}$ 
$<1)$ are representative of ebb-dominant sediment transport.

At Rochefort, sediment transport is thus ebb-dominated in $90 \%$ of the cases, compared to $65 \%$ at the river mouth. We could argue that the subdivision of zone 1 should also be applied to zone 3 . Longer rising tides $\left(T_{d}>1\right)$ with comparable flood and ebb peak velocities $\left(u_{p}>0.8\right)$ would then lead to flood-dominant sediment transport. This consideration would enhance the difference between Rochefort and the river mouth, with the latter becoming ebb-dominant only $38 \%$ of the time. These results are obtained by only considering the $2 \mathrm{D}$ modelled velocities. Consequently, all the processes associated with estuarine sediment dynamics are not considered. Further investigation, through 3D numerical modelling for example, remains needed to confirm these estimations.

\subsubsection{Morphological implications}

In terms of net sediment transport, the Rochefort area appears to be ebb-dominated most of the time, inducing net sediment export (Fig. 11). In contrast, the river mouth is more equally divided between periods of ebb and flood dominance. Flood dominance and net import at the mouth, which are associated with ebb dominance and net export at Rochefort suggest that the intermediate zone between those two locations is prone to sediment accumulation. According to Figs. 7 and 8, this configuration occurs mostly during the transition from spring to neap tides.

These modelling results are consistent with measurements of sediment accretion on the mudflats in the estuary, because small variations are observed near the mouth $(8 \mathrm{~cm}$ per month) whereas upstream measurements show an accretion rates up to $40 \mathrm{~cm}$ per month during summer (Coulombier et al., 2013). Sediment fluxes calculated with 3D hydrodynamic modelling and turbidity measurements also suggest alternations between net import and net export at the river mouth, which are largely determined by the spring-neap variations of the tide (Toublanc et al., 2013).

A switch from flood to ebb dominance caused by sedimentary infilling and flat formation and/or extension has been discussed by many authors (Speer and Aubrey, 1985; Fortunato and Oliveira, 2005; Moore et al., 2009). In the Charente estuary case, we can wonder whether the accumulation of sediment observed and suggested by this study could lead to a change in tidal propagation and, therefore, in net sediment transport. The relative equilibrium reached at the river mouth suggests that the possible morphological changes induced by tidal asymmetry in sediment transport are not sufficiently large to alter the system dynamics. However, strong siltation (estimated up to 1 meter in a month) was observed farther upstream, close to the dam, and remains an issue of concern for the management of the area.

\subsubsection{Turbidity maximum}

As demonstrated by Allen et al. (1980), tidal asymmetry is a driving mechanism leading to the formation of a turbidity maximum in macrotidal estuaries. Because tidal asymmetry in the Charente estuary is strongly dependent on the spring-neap tidal cycle, turbidity maximum dynamics should also be partly determined by this cycle. Previous work has demonstrated that neap tides favour sedimentation and the depletion of the turbidity maximum, whereas spring tides favour resuspension and turbidity maximum extension (Allen et al., 1980; Dyer, 1997). In addition to these dynamics, which are related to the strength of current velocities, fortnightly asymmetry inversions could also 
play a key role in the turbidity maximum. The transition from spring to neap tides is characterised by ebb-dominant current velocities at Rochefort, in contrast to flood-dominant velocities at the river mouth (Figs. 7 and 8), which could lead to turbidity maximum concentration and trapping in an intermediate zone, where current velocities would be neither ebb- nor flood-dominated. Inversely, the transition from neap to spring tides would favour the extension and downstream movement of the turbidity maximum, due to ebb dominance at both locations.

\section{Conclusion}

A temporally and spatially dependent asymmetry is observed in the Charente estuary and is reproduced by the model developed in this study. Parameters such as $V_{s} / V_{c}$ and $a / h$ (Friedrichs and Aubrey, 1988) cannot fully represent the tidal asymmetry, because no time-dependent factor is considered. Moreover, considering only the relative importance of M2 and M4 in phase and amplitude ignores the strong impact of S2 and of the compound constituent MS4, which is demonstrated in this paper. Modifying the bathymetry of the estuary also alters the response in terms of asymmetry dominance. These results confirm that both the incident tide and the estuarine morphology play a significant role in the Charente tidal asymmetry. To our knowledge, no other studies have observed such a fortnightly dependent tidal asymmetry in other macrotidal estuaries under the influence of a semidiurnal tide. Time-dependent asymmetry inversions have been studied with mixed tidal regimes (Jewell et al., 2012; Nidzieko and Ralston, 2012) or after major morphological changes (Boon and Byrne, 1981; Bolle et al., 2010).

Net sediment transport calculations suggest that accumulation occurs between the river mouth and Rochefort, which is confirmed by observations. This result could lead to major changes in the management of dredgings, because this accumulation would most likely happen during the transition from spring to neap tides. Further investigation is needed to determine the possible impact of this behaviour on the long-term morphological evolution of the Charente estuary.

A better understanding of the impact of asymmetry inversion on sediment dynamics could be achieved by applying the different configurations developed in this study to a nested 3D hydro-sedimentary model. Net sediment transport calculations at different locations and turbidity maximum modelling would allow a confirmation of the tendencies noted in this paper. The effects on mixing and stratification could also be investigated.

\section{Acknowledgements}

The authors gratefully acknowledge funding from the Conseil Général of Charente Maritime, the Poitou-Charentes Region, the CNRS, the FEDER and the University of La Rochelle. Xavier Bertin is particularly thanked for his help and review of this study. The REFMAR portal is also acknowledged for providing the tide gauge data, as is Ifremer for the bathymetry and the MARS-3D code. The authors thank Florence Cornette, Philippe Geairon, Olivier Le Moine, Stéphane Robert and Jean-Luc Seugnet for their valuable help on the ADCP campaign. 


\section{References}

Allen, G. P., Salomon, J. C., Bassoullet, P., Penhoat, Y. D., de Grandpré, C., 1980. Effects of tides on mixing and suspended sediment transport in macrotidal estuaries. Sedimentary Geology 26 (1-3), 69-90.

Aubrey, D. G., Speer, P. E., 1985. A study of non-linear tidal propagation in shallow inlet / estuarine systems part I : observations. Estuarine, Coastal and Shelf Science 21, 185-205.

Battisti, D. S., Clarke, A. J., 1982. A simple method for estimating barotropic tidal currents on continental margins with specific application to the M2 tide off the Atlantic and Pacific coasts of the United States. Journal of Physical Oceanography 12, 8-16.

Bertin, X., Bruneau, N., Breilh, J.-F., Fortunato, A. B., Karpytchev, M., 2012. Importance of wave age and resonance in storm surges: The case Xynthia, Bay of Biscay. Ocean Modelling 42, 16-30.

Bertin, X., Chaumillon, E., Sottolichio, A., Pedreros, R., 2005. Tidal inlet response to sediment infilling of the associated bay and possible implications of human activities: the Marennes-Oléron Bay and the Maumusson Inlet, France. Continental Shelf Research 25 (9), $1115-1131$.

Bolle, A., Wang, Z. B., Amos, C., De Ronde, J., 2010. The influence of changes in tidal asymmetry on residual sediment transport in the Western Scheldt. Continental Shelf Research 30 (8), 871-882.

Boon, J. D., 1988. Temporal variation of shallow-water tides in basin-inlet systems. In: Aubrey, D., Weishar, L. (Eds.), Hydrodynamics and sediment dynamics of tidal inlets. Springer-Verlag, New York, pp. 125 - 136.

Boon, J. D., Byrne, R. J., 1981. On basin hypsometry and the morphodynamic response of coastal inlet systems. Marine Geology 40, $27-48$.

Brown, J., Davies, A., 2010. Flood/ebb tidal asymmetry in a shallow sandy estuary and the impact on net sand transport. Geomorphology 114 (3), 431-439.

Castaing, P., Allen, G. P., 1981. Mechanisms controlling seaward escape of suspended sediment from the Gironde: A macrotidal estuary in France. Marine Geology 40 (1-2), 101-118.

Coulombier, T., Toublanc, F., Brenon, I., 2013. Seasonal monitoring of sediments dynamics in a highly turbid estuary (Charente Estuary, France): source and sink of the turbidity maximum. In: Proceedings of the 7th International Conference on Coastal Dynamics. pp. $387-396$.

Dronkers, J., 1986. Tidal asymmetry and estuarine morphology. Netherlands Journal of Sea Research 20 (2-3), 117-131.

Dyer, K., 1997. Estuaries: a Physical Introduction. Wiley, London.

Fischer, H., 1972. Mass transport mechanisms in partially stratified estuaries. Journal of Fluid Mechanics 53 (4), 671-687.

Flinchem, E., Jay, D., 2000. An Introduction to Wavelet Transform Tidal Analysis Methods. Estuarine, Coastal and Shelf Science 51 (2), 177-200.

Fortunato, A. B., Oliveira, A., 2005. Influence of Intertidal Flats on Tidal Asymmetry. Journal of Coastal Research 215 (1), $1062-1067$.

Friedrichs, C., Aubrey, G., 1988. Non-linear tidal distortion in shallow estuaries : a synthesis. Estuarine, Coastal and Shelf Science 27, $521-545$.

Fry, A., Aubrey, G., 1990. Tidal velocity asymmetries and bedload transport in shallow embayment. Estuarine, Coastal and Shelf Science 30, $453-473$.

Grinsted, A., Moore, J. C., Jevrejeva, S., 2004. Application of the cross wavelet transform and wavelet coherence to geophysical time series. Nonlinear Processes in Geophysics 11, 561-566.

Hasan, G. J., van Maren, D. S., Fatt, C. H., 2013. Numerical study on mixing and stratification in the ebb-dominant Johor estuary. Journal of Coastal Research 286, 201-215.

Huang, H., Chen, C., Blanton, J. O., Andrade, F. A., 2008. A numerical study of tidal asymmetry in Okatee Creek, South Carolina. Estuarine, Coastal and Shelf Science 78 (1), 190-202.

Jewell, S. A., Walker, D. J., Fortunato, A. B., 2012. Tidal asymmetry in a coastal lagoon subject to a mixed tidal regime. Geomorphology 138 (1), 171-180.

Lazure, P., Dumas, F., 2008. An external-internal mode coupling for a 3D hydrodynamical model for applications at regional scale (MARS). Advances in Water Resources 31 (2), 233-250.

Le Cann, B., 1990. Barotropic tidal dynamics of the Bay of Biscay shelf. Continental Shelf Research 10 (8), $723-758$.

Le Roy, R., Simon, B., 2003. Réalisation et validation d'un modèle de marée en Manche et dans le Golfe de Gascogne. Application à la réalisation d'un nouveau programme de réduction des sondages bathymétriques. In: Rapport technique, EPSHOM, Rapport n002/03. 
Li, M., Zhong, L., Boicourt, W. C., 2005. Simulations of Chesapeake Bay estuary: Sensitivity to turbulence mixing parameterizations and comparison with observations. Journal of Geophysical Research 110 (C12), C12004.

Ma, G., Shi, F., Liu, S., Qi, D., 2011. Hydrodynamic modeling of Changjiang Estuary: Model skill assessment and large-scale structure impacts. Applied Ocean Research 33 (1), 69-78.

MacCready, P., Geyer, W. R., 2010. Advances in Estuarine Physics. Annual Review of Marine Science 2 (1), 35-58.

Manoj, N. T., Unnikrishnan, A. S., Sundar, D., 2009. Tidal asymmetry in the Mandovi and Zuari estuaries, the west coast of India. Journal of Coastal Research 25 (6), 1187-1197.

Mehta, A., 1991. Review notes on cohesive sediment erosion. In: Proceedings of Coastal Sediments '91. pp. 40-53.

Mehta, A., Parchure, T., 2000. Surface erosion of fine-grained sediment revisited. In: Flemming, B., Delafontaine, M., Liebezeit, G. (Eds.), Muddy coast dynamics and ressource management. Elsevier, Amsterdam.

Moore, R. D., Wolf, J., Souza, A. J., Flint, S. S., 2009. Morphological evolution of the Dee Estuary, Eastern Irish Sea, UK: A tidal asymmetry approach. Geomorphology 103 (4), 588-596.

Nidzieko, N. J., Ralston, D. K., 2012. Tidal asymmetry and velocity skew over tidal flats and shallow channels within a macrotidal river delta. Journal of Geophysical Research 117 (C3), 1-17.

Pawlowicz, R., Beardsley, B., Lentz, S., 2002. Classical tidal harmonic analysis including error estimates in MATLAB using T_TIDE. Computers \& Geosciences $28(8), 929-937$.

Prandle, D., 2003. Relationships between tidal dynamics and bathymetry in strongly convergent estuaries. Journal of Physical Oceanography 33 (12), 2738-2750.

Ravail, B., Heral, M., Maestrini, S., Robert, J.-M., 1988. Incidence du débit de la Charente sur la capacité biotique du bassin ostréicole de Marennes-Oléron. Journal de Recherche Océanographique 13, 48-52.

Speer, P. E., Aubrey, D. G., 1985. A study of non-linear tidal propagation in shallow inlet / estuarine systems part II : theory. Estuarine, Coastal and Shelf Science 21, 207-224.

Speer, P. E., Aubrey, D. G., Friedrichs, C., 1991. Nonlinear hydrodynamics of shallow tidal inlet/bay systems. In: Parker, B. B. (Ed.), Tidal Hydrodynamics. John Wiley, New York, pp. 321-339.

Strady, E., Kervella, S., Blanc, G., Robert, S., Yves Stanisière, J., Coynel, A., Schäfer, J., 2011. Spatial and temporal variations in trace metal concentrations in surface sediments of the Marennes Oléron Bay. Relation to hydrodynamic forcing. Continental Shelf Research 31 (9), 9971007.

Tesson, M., 1973. Aspects dynamiques de la sédimentation dans la baie de Marennes-Oléron (France). Ph.D. thesis, Bordeaux 1.

Tolhurst, T., Black, K., Paterson, D., Mitchener, H., Termaat, G., Shayler, S., 2000. A comparison and measurement standardisation of four in situ devices for determining the erosion shear stress of intertidal sediments. Continental Shelf Research 20 (10-11), 1397-1418.

Toublanc, F., Brenon, I., Coulombier, T., Le Moine, O., 2013. Salinity and suspended sediment dynamics in response to forcing changes in a small macrotidal estuary (Charente, France). In: Proceedings of the 7th International Conference on Coastal Dynamics. pp. 1707-1718.

Wang, Y.-H., Ridd, P. V., Wu, H.-L., Wu, J.-X., Shen, H.-T., 2008. Long-term morphodynamic evolution and the equilibrium mechanism of a flood channel in the Yangtze Estuary (China). Geomorphology 99 (1-4), 130-138.

Wang, Z., Jeuken, M., Gerritsen, H., de Vriend, H., Kornman, B., 2002. Morphology and asymmetry of the vertical tide in the Westerschelde estuary. Continental Shelf Research 22 (17), 2599-2609.

Wang, Z. B., Jeuken, C., Vriend, H. J. D., 1999. Tidal asymmetry and residual sediment transport in estuaries.

Willmott, C. J., 1981. On the validation of models. Physical Oceanography 2, 184-194.

Xing, Y., Ai, C., Jin, S., 2012. A three-dimensional hydrodynamic and salinity transport model of estuarine circulation with an application to a macrotidal estuary. Applied Ocean Research 39, 53-71. 